\title{
PENGETAHUAN DAN PERAN KELUARGA DALAM PERILAKU MEROKOK DI NGLAMPENGAN BANTUL TAHUN 2018
}

\author{
Woro Ispandiyah \\ STIKES Surya Global Yogyakarta
}

\begin{abstract}
Background: Based on the information Head of Hamlet Nglampengan smoking is still the main topic that can cause very harmful effects, especially the more dominant inhaling cigarette smoke, the activity has become a hobby among people, especially men in Nglampengan Village Temuwuh Village Dlingo District, Bantul Regency. Awareness, customs and culture are some of the factors that make smoking a common thing, although smokers know the danger and its impact, but still do. The general purpose of this research is to know the influence of knowledge and family role to smoking behavior in Nglampengan Village Temuwuh Village Dlingo District, Bantul Regency. Method: The research type is descriptive quantitative research with crosssectional research design. The population in this study as many as 53 heads of households where researchers took from the population of head of household Nglampengan Village Temuwuh Village District DlingoBantul Regency is still actively smoking in the house. Sampling using samples saturated as many as 53 household heads. Result: The result of Chi Square test shows that there is no effect of between knowledge with smoking behavior with result of significant value (Pvalue) influence between knowledge with smoking behavior is 1.000 (Pvalue $>\alpha$ ). The influence of family role with smoking behavior with the result of significant value (Pvalue) equal to 0.037 $(P v a l u e<\alpha)$. Conclusion: There is not significant influencebetween knowledge and smoking behavior, the influenceof family role with smoking behavior.
\end{abstract}

Keywords: Knowledge, Family Roles, and Smoking Behavior.

\section{PENDAHULUAN}

Rokok sampai saat ini masih menjadi salah satu masalah kesehatan utama di dunia. World Health Organization (WHO) melaporkan bahwa rokok telah membunuh setengah dari jumlah seluruh perokok. Asap rokok mengandung lebih dari 4000 zat kimia berbahaya dan lebih dari 43 diantaranya diketahui merupakan zat penyebab kanker. Asap rokok tidak hanya berbahaya untuk perokok itu sendiri, tetapi juga berdampak pada orang-orang disekelilingnya. Menurut data Riset Kesehatan Dasar (Riskesdas) tahun 2013, hampir sepertiga masyarakat Indonesia adalah perokok (Riskesdas, 2013).

Indonesia merupakan negara ketiga di dunia dengan angka prevalensi perokok terbanyak setelah Cina dan India yaitu sebesar 4,8\% (WHO, 2008 dalam Tobacco Control Support Center, 2012). Pada tahun 2009, Indonesia menempati peringkat keempat dengan jumlah perokok terbanyak di dunia yakni sebesar 260.800 (Tobacco Atlas, 2009 dalam Tobacco Control Support Center, 2012). Pada tahun 2013 proporsi Indonesia adalah 29,3\% (Riskesdas, 2013). 
Prevalensi perokok di DIY sebesar 31,6\% dan sebanyak 66,1\% masih merokok di dalam rumah (Dinkes, 2013). Dari hasil tersebut, tidak mengherankan jika persentase perokok pasif cukup tinggi karena perokok biasa merokok di dalam rumahnya sendiri. Sedangkan jika dilihat dari statusnya, perokok rumah tangga didominasi oleh suami atau kepala rumah tangga (Riskesdas, 2013).

Berdasarkan yang dilakukan oleh peneliti pada bulan September 2017, di wilayah Kabupaten Bantul yang terdiri dari 27 Puskesmas sudah melaporkan persentase seluruh masyarakat wilayah kerja masng-masing yang berperilaku hidup bersih dan sehat salah satunya yaiu pada indikator ke-10 tentang merokok, dari hasil terendah yaitu di Puskesmas Dlingo I dengan 41,94\% (Dinkes Kabupaten Bantul, 2016).

Berdasarkan yang dilakukan peneliti di Puskesmas Dlingo I melakukan observasi dan wawancara langsung di Bidang Promosi Kesehatan pada Tahun 2016 terdapat Desa dengan persentase terendah yaitu di Desa Temuwuh dengan persentase terendah $55,55 \%$ yang artinya masih terdapat masyarakat yang merokok didalam rumah, yang diakibatkan beberapa faktor variabel.

Berdasarkan yang dilakukan peneliti di Puskesmas Dlingo I melakukan observasi dan wawancara langsung di Bidang Promosi Kesehatan pada Tahun 2016 populasi 148 kepala rumah tangga yang ada di Dusun Ngalmpengan dengan jumlah 112 kepala rumah tangga yang masih merokok didalam rumah dan dengan jumlah 36 kepala rumah tangga yang sudah tidak merokok didalam rumah, perilaku merokok yang menjadi permasalahan besar karena kurangnya pengetahuan akibat bahaya merokok didalam rumah dan peran keluarga yang dapat mendorong anggota keluarga lainnya ikut merokok.

Berdasarkan latar belakang masalah tersebut, peneliti mengambil judul penelitian tentang "Pengaruh Pengetahuan dan Peran Keluarga terhadap Perilaku Merokok di Dusun Nglampengan Desa Temuwuh Kecamatan Dlingo Kabupaten Bantul”.

\section{METODE PENELITIAN}

Jenis Penelitian ini adalah penelitian deskriptif kuantitatif dengan rancangan penelitian Cross-Sectional. penelitian deskriptif adalah penelitian yang dimaksudkan untuk menyelidiki keadaan, kondisi, atau hal lain-lain yang sudah disebutkan, yang hasilnya dipaparkan dalam bentuk laporan penelitian (Arikunto, 2014).

\section{a. Populasi Dan Sampel}

1. Populasi pada penelitian ini semua kepala keluarga sebanyak 112 kepala rumah tangga di Dusun Nglampengan Desa Temuwuh Kecamatan Dlingo Kabupaten Bantul pada tahun 2017.

2. Sampel dalam penelitian mengambil sampel 53 kepala rumah tangga yang masih merokok didalam rumah dari jumlah kepala rumah tangga di Dusun Nglampengan Desa Temuwuh Kecamatan Dlingo Kabupaten Bantul pada tahun 2017.

\section{b. Teknik Pengumpulan Data}

1. Data Primer

Data primer adalah secara langsung diambil dari objek atau objek penelitian oleh peneliti 
perorangan maupun organisasi (Riwidikdo, 2012).

Pengumpulan data dilakukan dengan menggunakan metode:
a. Studi Pustaka
b. Dokumentasi
c. Kuesioner

2. Data Sekunder

Data sekunder adalah data yang didapat secara tidak langsung dari objek penelitian.

Peneliti mendapatkan data yang sudah jadi yang dikumpulkan oleh pihak lain dengan berbagai cara atau metode baik secara komersial maupun non komersial (Riwidikdo, 2012).

\section{c. Teknik Analisis Data}

Teknik analisis data terdiri dari analisis univariate dan bivariate. Adapun untuk analisis univariate menjelaskan masing-masing variabel yang diteliti. Adapun analisis bivariate yang lain menggunakan analisis chi square.

\section{HASIL PENELITIAN}

1. Karakteristik Responden Penelitian

a. Karakteristik Responden Berdasarkan Umur

Tabel 1. Karakteristik Responden Berdasarkan Umur Di Dusun Nglampengan Bantul Tahun 2018

\begin{tabular}{llcc}
\hline No & $\begin{array}{l}\text { Kelompok } \\
\text { Umur }\end{array}$ & Jumlah & Presentase \\
\hline 1 & $<25$ & 6 & $11.3 \%$ \\
2 & $26-40$ & 7 & $13.2 \%$ \\
3 & $41-55$ & 21 & $39.6 \%$ \\
4 & $56-70$ & 19 & $35.8 \%$ \\
5 & $>70$ & 0 & $0 \%$ \\
\hline & Jumlah & $\mathbf{5 3}$ & $\mathbf{1 0 0 \%}$ \\
\hline
\end{tabular}

b. Karakteristik Responden Berdasarkan Jenis Kelamin

Tabel 2. Karakteristik Responden Berdasarkan Jenis Kelamin Di Dusun Nglampengan, Bantul Tahun 2018

\begin{tabular}{ccc}
\hline $\begin{array}{c}\text { Jenis } \\
\text { Kelamin }\end{array}$ & Jumlah & Persentase \\
\hline Laki-laki & 53 & $100 \%$ \\
\hline Jumlah & $\mathbf{5 3}$ & $\mathbf{1 0 0 \%}$ \\
\hline
\end{tabular}

c. Karakteristik Berdasarkan Agama

Tabel 1. Karakteristik Responden Berdasarkan Agama Di Dusun Nglampengan Bantul Tahun 2018

\begin{tabular}{ccc}
\hline Agama & Jumlah & Persentase \\
\hline Islam & 53 & $100 \%$ \\
\hline Jumlah & $\mathbf{5 3}$ & $\mathbf{1 0 0 \%}$ \\
\hline
\end{tabular}

d. Karakteristik Responden Berdasarkan Tinggal Bersama

Tabel 4. Karakteristik Responden Berdasarkan Tinggal Bersama Di Dusun Nglampengan, Bantul Tahun 2018

\begin{tabular}{llll}
\hline No & $\begin{array}{l}\text { Tinggal } \\
\text { Bersama }\end{array}$ & Jumlah & Persentase \\
\hline 1 & Pasangan & 35 & $66.0 \%$ \\
& (Suami/Istri) & & $7.5 \%$ \\
2 & Anak/menantu & 4 & $24.5 \%$ \\
3 & Orangtua & 13 & $1.9 \%$ \\
4 & Sendiri & 1 & $\mathbf{1 0 0 . 0 \%}$ \\
\hline & Total & $\mathbf{5 3}$ & \\
\hline
\end{tabular}
e. Karakteristik Responden Berdasarkan Pendidikan

Tabel 5. Karakteristik Responden Berdasarkan Pendidikan Di Dusun Nglampengan Bantul Tahun 2018 


\begin{tabular}{llcc}
\hline No Pendidikan & Jumlah & Persentase \\
\hline 1 & Tidak & 5 & $9.4 \%$ \\
& Sekolah & & $45.3 \%$ \\
2 & Tamat SD & 24 & $35.8 \%$ \\
3 & Tamat SLTP & 19 & $7.5 \%$ \\
4 & Tamat SLTA & 4 & $1.9 \%$ \\
5 & Perguruan & 1 & $\mathbf{1 0 0 \%}$ \\
\hline & Tinggi & & \\
\hline
\end{tabular}

f. Karakteristik Berdasarkan Pekerjaan

Tabel 6. Karakteristik Responden Berdasarkan Pekerjaan Di Dusun Nglampengan, Bantul Tahun 2018

\begin{tabular}{llll}
\hline No & Pekerjaan & Jumlah & Persentase \\
\hline 1 & $\begin{array}{l}\text { Tidak } \\
\text { bekerja }\end{array}$ & 11 & $5.7 \%$ \\
2 & $\begin{array}{l}\text { Tani/dagang } \\
\text { /buruh }\end{array}$ & 40 & $75.5 \%$ \\
3 & Wiraswasta & 5 & $9.4 \%$ \\
4 & PNS/ & 3 & $5.7 \%$ \\
& Karyawan & 2 & $3.8 \%$ \\
5 & Lain-lain & 2 & $\mathbf{1 0 0 \%}$ \\
\hline & Jumlah & $\mathbf{5 3}$ & \\
\hline
\end{tabular}

\section{Uji Normalitas}

Normalitas adalah suatu alat statistik yang sangat penting untuk menaksir dan meramalkan peristiwa-peristiwa yang sangat luas. Disebut juga dengan distribusi Gauss merupakan distribusi data kuantitatif kontinyu atau variabel $\mathrm{X}$ yang tersebar secara merata dan simetris. Distribusi dikatakan normal apabila nilai standar skewness yang diperoleh dari nilai skewness dibagi dengan standar errorof skewness bernilai -2 sampai 2 (Riwidikdo, 2012).

Tabel 7. Hasil Normalitas Variabel Pengetahuan dan Perilaku Tahun 2018

\begin{tabular}{ccc}
\hline & Pengetahuan & Perilaku \\
\hline N Normal & 53 & 53
\end{tabular}

$\begin{array}{lcc}\text { Parameter } & 6.42 & 5.30 \\ \text { rs } & & \\ \text { Mean } & 7.00 & 6.00 \\ \text { Median } & 7 & 8 \\ \text { Mode } & 0.819 & 2.932 \\ \text { Std. } & -1.354 & -0.557 \\ \text { Skewnes } & & \\ \text { Std. Error } & 0.327 & 0.327\end{array}$

Berdasarkan tabel 7 menunjukkan bahwa variabel pengetahuan memiliki nilaiskewness -1.354 dibagi dengan nilai standar errorof skewness 0,327 diperoleh nilai $-4,14$ dapat dikatakan distribusinya tidak normal. Untuk variabel perilaku memiliki nilaiskewness $-0,557$ dibagi dengan nilai standar errorof skewness 0,327 diperoleh nilai $-1,70$ dapat dikatakan distribusinya normal.

\section{Analisis Univariat}

a. Pengetahuan

Tabel 8. Distribusi Frekuensi Pengetahuan Di Dusun Nglampengan, Bantul Tahun 2018

\begin{tabular}{lcc}
\hline Pengetahuan & Frekuensi & Persentase \\
\hline Baik & 31 & $58.5 \%$ \\
Tidak Baik & 22 & $41.5 \%$ \\
\hline Jumlah & $\mathbf{5 3}$ & $\mathbf{1 0 0 \%}$ \\
\hline
\end{tabular}

Data yang tercantum dalam tabel 4.8 dapat diketahui bahwa responden pada sampel dengan pengetahuan yang masuk dalam kategori baik sebanyak 31 responden $(58.5 \%)$ dan tidak baik sebanyak 22 responden (41.5\%).

b. Peran Keluarga

Tabel 9. Distribusi Frekuensi Peran Keluarga Di Dusun Nglampengan, Bantul Tahun 2018 


\begin{tabular}{lcc}
\hline $\begin{array}{l}\text { Peran } \\
\text { Keluarga }\end{array}$ & Frekuensi & Persentase \\
\hline Baik & 24 & $45.3 \%$ \\
Cukup & 25 & $47.2 \%$ \\
Kurang & 4 & $7.5 \%$ \\
\hline Jumlah & $\mathbf{5 3}$ & $\mathbf{1 0 0 \%}$ \\
\hline
\end{tabular}

Data yang tercantum dalam tabel 4.9 dapat diketahui bahwa responden pada sampel dengan peran keluarga yang masuk dalam kategori baik sebanyak 24 responden $(45.3 \%)$, cukup sebanyak 25 responden $(47.2 \%)$ dan untuk kategori kurang sebanyak 4 responden $(7.5 \%)$.

c. Perilaku Merokok

Tabel 10. Distribusi Frekuensi Perilaku Merokok Di Dusun Nglampengan, Temuwuh, Dlingo, Bantul Tahun 2018

\begin{tabular}{lcc}
\hline $\begin{array}{l}\text { Perilaku } \\
\text { Merokok }\end{array}$ & Frekuensi & Persentase \\
\hline Berat & 23 & $43.4 \%$ \\
$\begin{array}{l}\text { Tidak } \\
\text { Berat }\end{array}$ & 30 & $56.6 \%$ \\
\hline \multicolumn{1}{c}{ Jumlah } & $\mathbf{5 3}$ & $\mathbf{1 0 0 \%}$ \\
\hline
\end{tabular}

Data yang tercantum dalam tabel

4.10 dapat diketahui bahwa responden pada sampel dengan perilaku merokok yang masuk dalam kategori berat sebanyak 23 responden (43.4\%) dan tidak berat sebanyak 30 responden $(56.6 \%)$.

\section{Analisis Bivariat}

a. Pengaruh pengetahuan dengan perilaku merokok

Tabel 11. Hasil Uji Crosstab Pengetahuan dengan Perilaku Merokok di Dusun Nglampengan Bantul Tahun 2018

\begin{tabular}{lccl}
\hline \multirow{2}{*}{ Pengetahuan } & \multicolumn{2}{c}{$\begin{array}{c}\text { Perilaku } \\
\text { Merokok }\end{array}$} & Total \\
\cline { 2 - 3 } & Berat & $\begin{array}{l}\text { Tidak } \\
\text { Berat }\end{array}$ & \\
\hline Baik & 13 & 18 & 31
\end{tabular}

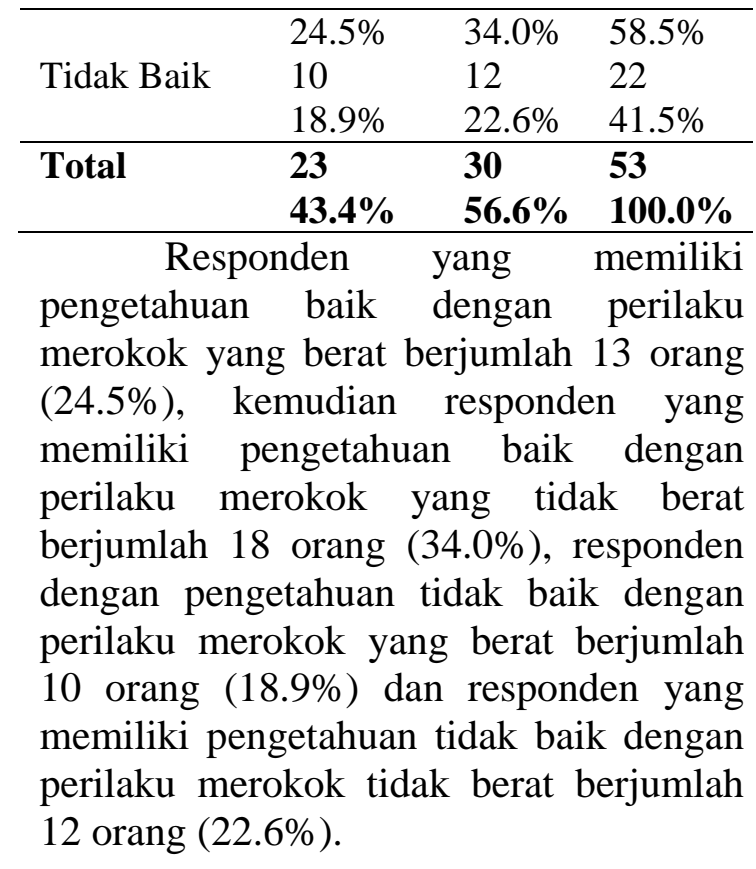

Tabel 12. Hasil Uji Chi Square Pengetahuan dengan Perilaku Merokok di Dusun Nglampengan Bantul Tahun 2018

\begin{tabular}{lccccc}
\hline & & & $\begin{array}{c}\text { Asymp. } \\
\text { Sig. (2- }\end{array}$ & $\begin{array}{c}\text { Exact } \\
\text { Sig. (2- }\end{array}$ & $\begin{array}{c}\text { Exact } \\
\text { Sig. (1- } \\
\text { sided) } \\
\text { sided) }\end{array}$ \\
\hline $\begin{array}{l}\text { Pearson Chi- } \\
\text { Square }\end{array}$ & $0.065^{\mathrm{a}}$ & 1 & .799 & & \\
$\begin{array}{l}\text { Continuity } \\
\text { Correction }\end{array}$ & .000 & 1 & 1.000 & & \\
$\begin{array}{l}\text { Likelihood } \\
\text { Ratio }\end{array}$ & .065 & 1 & .799 & & \\
$\begin{array}{l}\text { Fisher's Exact } \\
\text { Test }\end{array}$ & & & & & \\
N of Valid & & & & 1.000 & .510 \\
Cases & 53 & & & &
\end{tabular}

Hasil uji statistik dengan uji Chisquare menunjukkan bahwa nilai signifikan $\left(\mathrm{P}_{\text {value }}\right)$ pengaruh antara pengetahuan dengan perilaku merokok adalah 1,000 ( $\left.\mathrm{P}_{\text {value }}>\alpha\right)$, hal ini menunjukkan bahwa tidak ada pengaruh bermakna secara statistik antara pengetahuan dengan perilaku merokok.

b. Pengaruh peran keluarga terhadap perilaku merokok 
Tabel 13. Hasil Uji Crosstab Peran Keluarga dengan Perilaku Merokok di Dusun Nglampengan, Bantul Tahun 2018

\begin{tabular}{llll}
\hline \multirow{2}{*}{ Pengetahuan } & \multicolumn{2}{c}{$\begin{array}{c}\text { Perilaku } \\
\text { Merokok }\end{array}$} & \multirow{2}{*}{ Total } \\
\cline { 2 - 3 } & \multicolumn{2}{c}{ Berat } & $\begin{array}{l}\text { Tidak } \\
\text { Berat }\end{array}$ \\
\hline Baik & 11 & 13 & 24 \\
& $20.8 \%$ & $24.5 \%$ & $45.3 \%$ \\
Cukup & 8 & 17 & 25 \\
& $15.1 \%$ & $32.1 \%$ & $47.2 \%$ \\
Kurang & 4 & 0 & 42 \\
& $7.5 \%$ & $0 \%$ & $7.5 \%$ \\
\hline Total & $\mathbf{2 3}$ & $\mathbf{3 0}$ & $\mathbf{5 3}$ \\
& $\mathbf{4 3 . 4 \%}$ & $\mathbf{5 6 . 6 \%}$ & $\mathbf{1 0 0 . 0 \%}$ \\
\hline
\end{tabular}

Responden yang memiliki peran keluarga baik dengan perilaku merokok yang berat berjumlah 11 orang (20.8\%) dan peran keluarga baik dengan perilaku merokok tidak berat berjumlah 13 orang (24.5\%), kemudian responden yang memiliki peran keluarga cukup dengan perilaku merokok yang berat berjumlah 8 orang $(15.1 \%)$ dan peran keluarga cukup dengan perilaku merokok tidak berat berjumlah 17 orang (32.1\%), responden yang memiliki peran keluarga kurang dengan perilaku merokok yang berat berjumlah 4 orang $(7.5 \%)$, dan responden yang memiliki peran keluarga yang kurang dengan perilaku merokok yang tidak berat berjumlah 0 orang $(0.0 \%)$.

Tabel 14. Hasil Uji Chi Square Peran Keluarga dengan Perilaku Merokok di Dusun Nglampengan, Temuwuh, Dlingo, Bantul Tahun 2018

\begin{tabular}{lccc}
\hline & Value & Df & $\begin{array}{c}\text { Asymp. Sig. } \\
\text { (2-sided) }\end{array}$ \\
\hline $\begin{array}{l}\text { Pearson Chi- } \\
\text { Square }\end{array}$ & $6.597^{\mathrm{a}}$ & 2 & .037
\end{tabular}

\begin{tabular}{lrrr} 
Likelihood & 8.099 & 2 & .017 \\
Ratio & & & \\
N of Valid & \multicolumn{2}{c}{53} & \\
Cases $^{\text {b }}$ & \multicolumn{2}{l}{}
\end{tabular}

Hasil uji statistik dengan uji Chisquare menunjukkan bahwa nilai signifikan $\left(\mathrm{P}_{\text {value }}\right)$ pengaruh antara peran keluarga dengan perilaku merokok adalah $0,037\left(\mathrm{P}_{\text {value }}<\alpha\right)$, hal ini menunjukkan bahwa ada pengaruh bermakna secara statistik antara peran keluarga dengan perilaku merokok.

\section{PEMBAHASAN}

\section{Pengetahuan dengan peran keluarga di Dusun Nglampengan Desa Temuwuh Kecamatan Dlingo Kabupaten Bantul.}

Berdasarkan hasil analisa dapat diketahui bahwa jumlah responden di masyarakat Dusun Nglampengan Desa Temuwuh Kecamatan Dlingo Kabupaten Bantul yang memiliki pengetahuan baik yaitu $58.5 \%$ (31 responden) dan yang tidak baik $41.5 \%$ (22 responden).

Hasil Uji Crosstab menyatakan bahwa responden yang memiliki pengetahuan baik dengan perilaku merokok yang berat berjumlah 13 orang (24.5\%), kemudian responden yang memiliki pengetahuan baik dengan perilaku merokok yang tidak berat berjumlah 18 orang $(34.0 \%)$, responden dengan pengetahuan tidak baik dengan perilaku merokok yang berat berjumlah 10 orang (18.9\%) dan responden yang memiliki pengetahuan tidak baik dengan perilaku merokok tidak berat berjumlah 12 orang (22.6\%).

Hasil uji statistik dengan uji Chi-square menunjukkan bahwa nilai 
signifikan $\left(\mathrm{P}_{\text {value }}\right)$ pengaruh antara pengetahuan dengan perilaku merokok adalah 1,000 $\left(\mathrm{P}_{\text {value }}>\alpha\right)$, ini menunjukkan bahwa tidak ada pengaruh bermakna secara statistik antara pengetahuan dengan perilaku merokok. Hal ini disebabkan oleh ketidakseimbangan antara hasil statistik pengetahuan dengan perilaku merokok, untuk hasil dari pengetahuan menunjukkan bahwa responden yang memiliki pengetahan baik sebanyak 31 orang dan yang berpengetahuan tidak baik sebanyak 22 orang. Sedangkan untuk hasil dari perilaku merokok menunjukkan ada 23 orang yang perilaku merokok berat dan 30 orang yang perilaku merokok tidak berat, sedangkan untuk crosstab pengetahuan dengan perilaku merokok responden yang memiliki pengetahuan baik dengan perilaku merokok berat berjumlah 13 orang (24.5\%), kemudian responden yang memiliki pengetahuan baik dengan perilaku merokok tidak berat berjumlah 18 orang (34.0\%), responden yang memiliki pengetahuan tidak baik dengan perilaku merokok berat berjumlah 10 orang $(18.9 \%)$ dan responden yang memiliki pengetahuan tidak baik dengan perilaku merokok tidak berat berjumlah 12 orang (22.6\%). Maka dapat disimpulkan bahwa variabel $\mathrm{X}_{1}$ (Pengetahuan) lebih banyak hasil kategori baik dan vaiabel Y (Perilaku merokok) lebih sedikit kategori berat menjadikan tidak adanya pengaruh pengetahuan dengan perilaku merokok.

2. Peran keluarga dengan perilaku merokok di Dusun Nglampengan Desa Temuwuh

\section{Kecamatan Dlingo Kabupaten Bantul.}

Berdasarkan hasil analisa dapat diketahui bahwa jumlah responden di Dusun Nglampengan Desa Temuwuh Kecamatan Dlingo Kabupaten Bantul yang memiliki peran keluarga baik yaitu $45.3 \%$ (24 orang), yang cukup $47.2 \%$ (25 orang) dan yang kurang $7.5 \%$ (4 orang).

Hasil Uji Crosstab menyatakan bahwa responden yang memiliki peran keluarga baik dengan perilaku merokok yang berat berjumlah 11 orang $(20.8 \%)$ kemudian responden yang memiliki peran keluarga baik dengan perilaku merokok yang tidak berat berjumlah 13 orang $(24.5 \%)$, responden yang memiliki peran keluarga cukup dengan perilaku merokok berat berjumlah 8 orang $(15.1 \%)$ kemudian responden yang memiliki peran keluarga cukup dengan perilaku merokok yang tidak berat berjumlah 17 orang (32.1\%), dan responden yang memiliki peran keluarga kurang dengan perilaku merokok berat berjumlah 4 orang $(7.5 \%)$ kemudian responden yang memiliki peran keluarga kurang dengan perilaku merokok tidak berat berjumlah 0 orang $(0.0 \%)$.

Hasil uji statistik dengan uji Chi-square menunjukkan bahwa nilai signifikan $\left(\mathrm{P}_{\text {value }}\right)$ pengaruh antara peran keluarga dengan perilaku merokok adalah $0,037 \quad\left(\mathrm{P}_{\text {value }}<\alpha\right)$, hal ini menunjukkan bahwa ada pengaruh bermakna secara statistik antara 
peran keluarga dengan perilaku merokok.

\section{KESIMPULAN DAN SARAN}

Kesimpulan:

1. Tidak ada pengaruh antara pengetahuan dengan perilaku merokok di Dusun Nglampengan Desa Temuwuh Kecamatan Dlingo Kabupaten Bantul. Hal ini dapat dilihat dari hasil statistik dengan uji Chi-square dengan nilai $\mathrm{P}=1,000(\mathrm{P}$ $>0,05)$ menunjukkan bahwa pengetahuan tidak mempengaruhi secara signifikan dengan perilaku merokok di Dusun Nglampengan Desa Temuwuh Kecamatan Dlingo Kabupaten Bantul.

2. Ada pengaruh antara peran keluarga dengan perilku merokok di Dusun Nglampengan Desa Temuwuh Kecamatan Dlingo Kabupaten Bantul. Hal ini dapat dilihat dari hasil uji $C h i-$ square dengan nilai $\mathrm{P}=0,037(\mathrm{P}<$ $0,05)$ menunjukkan bahwa peran keluarga mempengaruhi secara signifikan dengan perilaku merokok di Dusun Nglampengan Desa Temuwuh Kecamatan Dlingo Kabupaten Bantul.

Saran:

1. Bagi masyarakat

a. Diharapkan agar masyarakat khususnya kepala rumah tangga lebih meningkatkan lagi kesadaran akan bahayanya merokok didalam rumah yang dapat menyebabkan bahaya bukan untuk dirinya sebagai perokok namun juga untuk seluruh anggota keluarga yang menempati rumah bersama si perokok tersebut, apalagi jika didalam rumah terdapat ibu hamil, balita atau seorang penderita penyakit yang rentan terhadap asap rokok.

b. Diharapkan untuk kepala rumah tangga yang merokok untuk tidak menjadi contoh dan melarang apabila ada anggota keluarga lain yang ingin mencoba atau sudah merokok tetapi belum menjadi pecandu rokok.

c. Diharapkan anggota keluarga saling mengingatkan apabila masih ada yang merokok didalam rumah untuk merokok di luar rumah karena dapat membahayakan anggota keluarga lainnya.

d. Diharapkan untuk anggota keluarga sebagai perokok pasif untuk lebih mengantisipasi diri dengan jaga jarak atau menjauh karena setiap harinya perokok pasif tidak harus menerima paparan asap rokok di rumah, karena perokok pasif berdampak lebih berat bahayanya bagi tubuh daripada perokok aktif.

2. Bagi Puskesmas

a. Diharapkan petugas puskesmas agar dapat mensosialisasikan tentang PHBS (Perilaku Hidup Bersih dan Sehat), melakukan pendekatan kepada masyarakat dan melakukan penyuluhan atau deklarasi secara menyeluruh kepada setiap dusun mengenai bahaya dan dampak yang ditimbulkan apabila merokok didalam rumah, agar perilaku hidup bersih dan sehat (PHBS) ke-10 dapat menjadi pedoman untuk diterapkan ke seluruh masyarakat.

b. Diharapkan Puskesmas membuat poster atau sticker bahaya 
merokok didalam rumah serta akibat yang ditimbulkan untuk dibagikan kepada seluruh warga masyarakat guna mencegah adanya kepala keluarga khususnya maupun anggota keluarga lainnya yang hobi merokok didalam rumah.

c. Diharapkan Puskesmas dapat membuka layanan konseling berhenti merokok yang dapat menarik perhatian masyarakat terutama kepala keluarga aktif perokok yang ingin berhenti merokok tetapi susah mengendalikannya bisa datang ke puskesmas untuk sharing pengalaman dan cara untuk berhenti merokok sampai benarbenar menghentikannya.

3. Bagi peneliti lain

Diharapkan peneliti lain yang ingin mengkaji permasalahan sejenis, agar dapat lebih memperluas cakupan wilayah sampel penelitian dan mencoba dengan variabel atau faktor perilaku merokok yang lainnya dan hasil penelitiannya dapat digeneralisasikan lebih baik lagi seperti variabel kesadaran, variabel kebiasaan, maupun faktor petugas kesehatan yang dapat mempengaruhi misalnya dari Puskesmas wilayah kerja yang kurang menjangkau seluruh fasilitas yang sangat bermanfaat untuk masyarakat.

\section{DAFTAR RUJUKAN}

Achar, Komang Ayu Heni. 2012. Aplikasi Praktis Asuhan Keperawatan Keluarga. Sagung Seto : Jakarta.

Agu. 2002. Pengaruh Kelompok Teman Sebaya Terhadap Perilaku Konsumtif Pada Remaja Puteri.
Alex. 2015. Hubungan Tingkat Pengetahuan dan Sikap Tentang Pictoral Health Warning (PHW) pada Kemasan Rokok dengan Motivasi Berhenti Merokok pada Siswa SMA Santun Pontianak.

Amyati. 2017. Buku Ajar Perencanaan dan Evaluasi Program Kesehatan. Stikes Surya Global Yogyakarta : Yogyakarta.

Arikunto, Suharsini. 2014. Prosedur Penelitian : Suatu Pendekatan Praktik. Rineka Cipta : Jakarta.

Asri, Nur. 2013. Hubungan Peran Petugas Kesehatan dan Media Informasi dengan Perilaku Seksual pada Ibu Pasca Nifas di Wilayah Kerja Puskesmas Peukan Bada Kabupaten Aceh Besar.

Bagus. 2002. Hakikat dan Makna Nilai Oleh Dudung Rahmat Hidayat Mulyadi Universitas Pendidikan Indonesia.

Darsono. 2008. Hubungan Perceived Service Quality dan Loyalitas: Peran Trust dan Satisfaction sebagai Mediator, The 2nd National Conference ukwms, Surabaya.

Dinas Kesehatan Kabupaten Bantul. 2016. Laporan Puskesmas Rekapitulasi PHBS Rumah Tangga tahun 2016 Yogyakarta : Dinas Kesehatan Bantul. http://temuwuh.bantulkab.go.id/in dex.php/first/artikel/32

Kementrian Kesehatan RI. 2013. Riset Kesehatan Dasar 2013. Jakarta. http://www.depkes.go.id/recource s/download/general/Hasil\%20Risk esdas\%202013.pdf

Maulana, Nova. 2014. Buku Ajar Sosiologi \& Antropologi 
Kesehatan. Nuha Medika : Yogyakarta.

Notoatmodjo, Soekidjo. 2011. Kesehatan Masyarakat Ilmu \& Seni. Rineka Cipta : Jakarta.

Notoatmodjo, Soekidjo. 2012. Metodelogi Penelitian Kesehatan. Rineka Cipta : Jakarta.

Novita dan Franciska. 2011. Promosi Kesehatan Dalam Pelayanan Kebidanan. Salemba Medika : Jakarta.

Nursalam. 2013. Metodologi Penelitian Ilmu Keperawatan. Salemba Medika : Jakarta Selatan.

Prayugo, Budi. 2016. Hubungan Peran Orangtua Terhadap Perilaku Merokok Siswa SMP N 1 Buayan.

Puskesmas Dlingo I. 2016. Rekapitulasi Tatanan PHBS Rumah Tangga Tahun 2017 : Puskesmas Dlingo I.

Riskesdas. 2013. Survei Perokok dan Kondisi Kesehatan Perokok di Wilayah Rural (Desa Cilebut Barat Kabupaten Bogor) dan Urban (Kelurahan Kalibata Kota Jakarta Selatan).

Riwidikdo, Handoko. 2012. Statistik Kesehatan : Belajar Mudah Teknik Analisis Data Dalam Penelitian Kesehatan. Nuha Medika : Yogyakarta.

Rukiah. 2014. Hubungan Dukungan Suami dengan Kecemasan Ibu Hamil dalam Menghadapi Persalinan di Puskesmas Gamping 1 Sleman Yogyakarta oleh Deta Pezani Universitas 'Aisyiyah Yogyakarta.

Setiadi. 2008. Konsep dan Proses Keperawatan Keluarga. Yogyakarta: Graha Ilmu.

Silowati, Lilis Nur. 2012. Hubungan Tingkat Pengetahuan Tentang
Merokok dengan Frekuensi Merokok pada Remaja Awal di Desa Gayam Kecamatan Sukoharjo Kabupaten Sukoharjo. Sugiyono. 2016. Statistika Untuk Penelitian. Alfabeta : Bandung.

Sundari, Ariska Hesti. 2014. Hubungan Antara Peran Keluarga dengan Perilaku Merokok pada Remaja Laki-laki Kelas XI di SMK Tunas Bangsa Sukoharjo.

Tim Penulis Poltekkes Depkes Jakarta I. 2010. Kesehatan Remaja Problem dan Solusinya. Salemba Medika: Jakarta.

Wawan dan Dewi. 2010. Teori \& Pengukuran Pengetahuan, Sikap, dan Perilaku Manusia. Nuha Medika : Yogyakarta. 